\title{
Tantangan dan Peluang Pembangunan Proyek Pembangkit Listrik Energi Baru Terbarukan (EBT) di Indonesia
}

\author{
Mohammad Ahsan \\ Fakultas Teknologi Bisnis dan Energi, Institut Teknologi PLN \\ ahsan@itpln.ac.id
}

\begin{abstract}
The purpose of this study is to find out the current state of Indonesia's electricity with New and Renewable Energy, analyze the challenges in the development of New and Renewable Energy, and analyze opportunities to develop Indonesia's electricity through sustainable development of New and Renewable Energy. Energy generation, analyzing the factors that support the development of New and Renewable Energy plants and analyzing the effect of economic growth, customer growth, connected power, and electricity sales with the development of New and Renewable Energy. The research design and methodology used are qualitative and quantitative methods by looking at the relationship between the variables of economic growth, plant growth, customer additions, and electricity sales related to the development of New and Renewable Energy in Indonesia. The findings in this study are that the construction of New and Renewable Energy plants is needed to answer environmental challenges and the company's growth, especially the increase in the number of customers, connected power and electricity sales. These findings provide an initial overview of systemic variables and patterns in the development of New and Renewable Energy in Indonesia.
\end{abstract}

Keywords: Power Generation, New Renewable Energy, economic growth, electricity sales growth

\begin{abstract}
ABSTRAK
Tujuan dari penelitian ini untuk mengetahui kondisi kelistrikan Indonesia saat ini yang kaitannya dengan Energi Baru Terbarukan (EBT), menganalisis tantangan dalam pembangunan EBT serta menganalisis peluang pengembangan kelistrikan Indonesia melalui pembangunan pembangkit EBT yang berkelanjutan, menganalisis factor yang mendukung pembangunan pembangkit EBT serta menganalisis pengaruh pertumbuhan ekonomi, pertumbuhan pelanggan, daya tersambung dan penjualan tenaga listrik dengan pengembangan EBT. Desain dan metodologi penilitian yang digunakan yaitu metode kualitatif dan kuantitatif dengan melihat hubungan antara variable pertumbuhan ekonomi, pertumbuhan pembangkit, penambahan pelanggan dan penjualan tenaga listrik terkait dengan pengembangan EBT di Indonesia. Temuan dalam penelitian ini bahwa pembangunan pembangkit EBT diperlukan untuk menjawab tantangan lingkungan dan pertumbuhan perusahaan khususnya peningkatan jumlah pelanggan, daya tersambung dan penjualan tenaga listrik. Temuan ini memberikan pandangan awal tentang variabel dan pola sistemik dalam pengembangan EBT di Indonesia.
\end{abstract}

Kata kunci: Pembangkit EBT, pertumbuhan ekonomi, pertumbuhan penjualan tenaga listrik 


\section{PENDAHULUAN}

Penggunaan energi primer dari sumber energi fosil untuk memenuhi kebutuhan kelistrikan Indonesia masih dominan dalam bauran energi di Indonesia, yaitu porsi pemanfaatan energi terbarukan masih tergolong sangat rendah dibanding dengan porsi penggunaan energi fosil juga masih sangat rendah jika dibandingkan dengan pemanfaatan energi terbarukan negara tetangga dan beberapa negara maju di dunia [1] [2]. Masih tingginya ketergantungan terhadap energi fosil di Indonesia menjadi pekerjaan rumah bagi pemerintah dalam upaya mengurangi ketergantungan terhadap energi fosil dengan cara meningkatkan pemanfaatan dan pengembangan sumber energi baru dan energi terbarukan (EBT) di sektor ketenagalistrikan, dengan tetap menjaga ketahanan energi nasional [3][4]. Kendala-kendala yang menjadi penghambat dalam pemanfaatan EBT di sektor ketenagalistrikan yaitu [3] [5]: 1) Dekarbonisasi menyebabkan terjadinya transisi energi membawa dampak perubahan global pada sector energi dan kelistrikan sementara peraturan dan implementasinya cenderung tertinggal dengan langkah perubahan. 2) Pemasalahan PT PLN (Persero) sebagai penyediaan tenaga listrik dengan kondisi over supplay dan take or pay, 3), Biaya pembangunan dan pengembangan EBT di Indonesia masih terbilang mahal dibanding dengan harga EBT negara lainbelum kompetitif dan 4) Tidak semua pembangkit EBT dapat diterima oleh sistem kelistrikan [5] [6]. Pertanyaannya opsi manakah yang akan dipilih pemerintah atau PLN; apakah mengganti seluruh pembangkit fosil menjadi pembangkit EBT atau memaksimalkan pembangkit Fosil eksisting dengan program memperbaiki performance pembangkit serta mengurangi emisi $\mathrm{CO} 2$ pembangkit tersebut. Upaya yang dapat dilakukan Pemerintah sebagai solusi dari hambatan-hambatan yang terjadi dalam pemanfaatan EBT di sektor ketenagalistrikan yaitu mengembangkan infrastruktur dan sistem kelistrikan di Indonesia, dan Merancang serta Memperbaiki Regulasi Pengembangan dan Pemanfaatan EBT di Sektor Ketenagalistrikan. Beberapa pilihan strategi bisnis untuk mengatasi kendala pengembangan EBT antara lain [7] [8]; a) meningkatkan performance pembangkit eksisting dan upaya mengurangi dampak CO2 dan ramah lingkungan misal (cofiring, gasifikasi batu bara, dII), b) pembangunan pembangkit EBT (PLTS, PLTB, PLTM, Hidro, dII) [9][10].

Penelitian terdahulu dalam peraturan di bidang ketenagalistrikan terus mengalami perubahan dengan berbagai pendekatan yang memiliki dampak yang cukup tinggi pada sektor secara keseluruhan[11]. Regulasi khusus untuk sektor EBT juga telah dibuat dalam dekade terakhir, menunjukkan kekhawatiran yang berkembang pada penggunaan sumber daya EBT [12]. Dalam penelitian yang lain [13], perhatian akademis meningkat pada logistik berkelanjutan dalam beberapa tahun terakhir, upaya penurunan rendah karbon dan dampaknya terhadap pengurangan jejak karbon masih kurang diteliti, studi empiris dengan data konsumsi energi atau emisi masih kurang meskipun hambatan yang menghambat pengurangan dampak gas rumah kaca - GRK di kawasan Asia-Pasifik juga tidak dipahami dengan baik. Tujuan dalam pengembangan pembangunan pembangkit EBT diperlukan untuk menjawab tantangan lingkungan dalam upaya untuk menurunkan emisi CO2 dan dampak GRK serta meningkatkan pertumbuhan perusahaan khususnya peningkatan jumlah pelanggan, daya tersambung dan penjualan tenaga listrik, sehingga harus menjadi perhatian semua pihak baik dari sisi akademisi, pemerintah dan perusahaan terkait. Originalitas penelitian ini yaitu temuan memberikan pandangan awal tentang variabel dan pola sistemik dalam pengembangan EBT di Indonesia yang mengikutkan peran aktif berbagai pihak dalam mengembangkan sumber daya energi Indonesia untuk mewujudkan 
pembangunan EBT dengan alasan lingkungan dan pertumbuhan ekonomi dan konsumsi energi. Kontribusi penelitian ini diharapkan; pertama, untuk pengembangan ilmu pengetahuan khususnya terkait dengan pengembangan EBT di Indonesia, kedua sebagai masukan bagi manajemen dalam pengambilan keputusan untuk pengembangan EBT dan ketiga menjadi referensi bagi penelitian selanjutnya dalam menganalisis pengembangan EBT. Penelitian ini menjadi penting karena penggunaan energi listrik semakin berkembang dan tantangan untuk merubah energi fosil ke EBT menjadi perhatian utama hampir seluruh dunia utamanya karena alasan lingkungan dan penyelamatan keberlangsungan alam ini [14][15]. Kebijakan Energi Nasional mengacu pada Paris Agreement tahun 2015 telah ditindaklanjuti dengan komitmen mewujudkan Net zero emissions pada tahun 2050 dengan perjanjian aliansi keuangan yang dibuat pada tahun 2021 telah menciptakan perubahan yang strategis, sebagai dukungan Paris Agreement 2015 berpengaruh terhadap peran pembiayaan global saat ini [8]. Terdapat 2 pengaruh besar yang oleh kebijakan Paris Agreement dari sisi pembiayaan yaitu, pertama divestasi pada aset intensif karbon dan kedua, memobilisasi kapital ke arah aset transisi energi rendah karbon. Dalam perjalanannya beberapa tahun terakhir ini, investor telah memberikan tekanan kepada perusahaan bahan bakar fosil melalui divestasi atau perjanjian untuk mendukung net zero emissions, sehingga menciptakan momentum ke arah aksi iklim yang lebih kuat. Kajian yang mengemukakan bahwa divestasi bahan bakar fosil hanya merupakan satu sisi dalam cerita ini [16]. Dampak lain yang menjadi hal penting adalah pergerakan dari menghindari risiko finansial yang berhubungan dengan perubahan iklim dan dukungan terhadap peluang investasi yang ditawarkan oleh transisi energi. Kebijakan Energi Nasional disingkat KEN adalah Kebijakan pengelolaan energi yang berdasarkan prinsip berkeadilan, berkelanjutan dan berwawasan lingkungan guna terciptanya kemandirian energi dan ketahanan energi nasional [17]. Kebijakan-kebijakan mengenai energi nasional yang dibentuk agar dapat dijadikan sebagai payung hukum dalam hubungan kebijakan pemerintah mengenai energi. Tujuan pengadaan KEN yaitu agar dapat dijadikan sebagai acuan dalam menata dan juga mengelola energi Indonesia di masa mendatang. KEN diterbitkan melalui Peraturan Pemerintah no. 79 Tahun 2014. Untuk mendukung upaya pencapaian sasaran KEN, maka penjabarannya diuraikan dalam Rencana Umum Energi Nasional - disingkat RUEN yaitu kebijakan Pemerintah Pusat mengenai rencana pengelolaan energi tingkat Nasional. Tujuan penelitian ini adalah pertama, mengetahui kebijakan-kebijakan pemanfaatan EBT secara nasional, kedua mengetahui hambatan dalam implementasi kebijakan terhadap optimalisasi pemanfaatan EBT dan solusi untuk mengoptimalkan pemanfaatan energi baru terbarukan di Indonesia dan ketiga untuk menganalisis faktor pendorong pemanfaatan energi terbarukan berdasarkan implementasi dan kendala yang terjadi dan berpegang pada upaya yang sudah dilakukan di negara negara yang sudah memanfaatkan energi terbarukan di dunia.

\section{METODOLOGI PENELITIAN}

Jenis penelitian ini menggunakan jenis penelitian kualitatif yaitu penelitian yang bertujuan menjelaskan secara kualitatif yang menggambarkan factor-faktor yang mendorong pertumbuhan EBT[18]. Dalam penggunaan data, data yang digunakan yaitu data sekunder dengan pola data tren yang diperoleh dari literatur dan dokumen perusahaan maupun peraturan yang mendukung analisis[19]. Beberapa data di olah untuk menghasilkan tabel agar tergambar hubungan data atau tabel dengan pembahasan dan permasalahan dalam penilaian ini. Pada Peraturan Pemerintah Nomor 79 Tahun 2014 
Tentang Kebijakan Energi Nasional [17], dijelaskan bahwa kebijakan energi nasional merupakan kebijakan Pengelolaan Energi yang berdasarkan prinsip berkeadilan, berkelanjutan, dan berwawasan lingkungan guna terciptanya Kemandirian Energi dan Ketahanan Energi Nasional. Dan penjabarannya tercermin dalam Pasal 3 tentang Kebijakan Energi dengan pendukung yang terdiri dari : 1). Kebijakan utama meliputi, a, ketersediaan energi untuk kebutuhan nasional, b. prioritas pengembangan energi, c. pemanfaatan sumber daya energi nasional dan d. cadangan energi nasional. Serta 2). Kebijakan pendukung meliputi: a. konservasi energi, konservasi sumber daya energi, dan diversifikasi energi, b. lingkungan hidup dan keselamatan; c. harga, subsidi, dan insentif energi, $d$. infrastruktur dan akses untuk masyarakat terhadap energi dan industri energi, e. penelitian, pengembangan, dan penerapan teknologi energi dan f. kelembagaan dan pendanaan. Diversifikasi Energi juga tercantum pada PP No 79 tahun 2014 yang pelaksanaannya antara lain melalui: percepatan penyediaan dan pemanfaatan berbagai jenis Sumber Energi Baru dan Sumber Energi Terbarukan; dan percepatan pemanfaatan tenaga listrik untuk penggerak kendaraan bermotor.

Penelitian menunjukkan bahwa investasi energi terbarukan akan menghasilkan tingkat pengembalian yang tinggi dan menciptakan lapangan pekerjaan. Inilah saatnya negara-negara mendorong energi terbarukan dan teknologi rendah karbon lainnya untuk menciptakan lapangan kerja baru dan memulihkan ekonomi dalam upaya untuk membangun kembali lebih baik pasca COVID-19[20].

Berikut adalah tiga alasan mengapa paket stimulus perlu mengikutsertakan investasi energi terbarukan untuk mendorong pertumbuhan EBT, yaitu:

1. Energi bersih menghasilkan keuntungan ekonomi beberapa kali lipat dari investasi awal. Disamping mendorong energi terbarukan, investasi ini juga akan membantu mitigasi risiko keuangan dan risiko lain dari perubahan iklim. Pada tahun 2030, 2,5 juta orang dan properti perkotaan senilai $\$ 42$ miliar akan terkena dampak banjir pesisir akibat perubahan iklim setiap tahunnya, sementara 30 juta orang dan properti perkotaan senilai $\$ 79$ miliar akan terkena dampak banjir sungai setiap tahunnya. Pendapatan dari EBT dijamin oleh kontrak jangka panjang berbasis biaya. Sektor ini telah menawarkan pengembalian yang disesuaikan dengan risiko dengan volatilitas yang lebih rendah dibandingkan dengan ekuitas berorientasi pendapatan lainnya [21]. (lihat Tabel 1) [16].

Tabel 1. Matrik Pegembalian Risiko Lima Tahun di Seluruh Aset Beroriaentasi Pendapatan Tabel 1 - Matrik Pengembalian Risiko Lima Tahun di Seluruh Aset Berorientasi Pendapatan

\begin{tabular}{|l|r|r|r|r|r|r|r|r|}
\hline & $\begin{array}{c}\text { Traditional } \\
\text { Energy Infra. }\end{array}$ & Clean Tech & REITs & Utilities & S\&P 500 & $\begin{array}{c}\text { Clean } \\
\text { Energy } \\
\text { Infra. }\end{array}$ & Global Infra. & MSCI ACWI \\
\hline 5-Year Returns & $5.0 \%$ & $38.0 \%$ & $7.0 \%$ & $9.0 \%$ & $16.0 \%$ & $19.0 \%$ & $8.0 \%$ & $14.0 \%$ \\
\hline Volatility (Annualized) & $26.3 \%$ & $33.3 \%$ & $22.5 \%$ & $21.4 \%$ & $19.1 \%$ & $18.0 \%$ & $16.9 \%$ & $15.5 \%$ \\
\hline Sharpe Ratio & 0.10 & 1.40 & 0.40 & 0.50 & 0.90 & 1.10 & 0.50 \\
\hline
\end{tabular}

Source: Goldman Sachs Asset Management.

2. Ketidakstabilan harga bahan bakar fosil menjadi peluang global untuk mempercepat peralihan ke energi bersih. Industri bahan bakar fosil adalah salah satu industri yang paling terdampak oleh krisis virus corona, dengan tingkat kehilangan nilai pasar perusahaan minyak, gas dan petrokimia terkemuka rata- 
rata 45 persen. Sejak awal tahun ini, permintaan minyak mengalami penurunan paling tajam dalam seperempat abad terakhir. Harga minyak mentah di Amerika Serikat mencapai titik negatif untuk pertama kalinya dalam sejarah. Anjuran lockdown jelas memberatkan industri bahan bakar fosil, namun keruntuhan struktural ini tidak mengagetkan. Selama dekade terakhir, pengeluaran industri bahan bakar fosil untuk pembelian kembali saham dan dividen lebih tinggi dari penghasilan yang diterima, sehingga energi menjadi sektor dengan kinerja terburuk sejak 2009 dari 11 sektor dalam indeks S\&P500. Selain itu, menyadari risiko keuangan investasi intensif karbon yang terus meningkat, lembaga-lembaga keuangan besar dunia juga mulai meninggalkan bahan bakar fosil. Menurut Center for International Environmental Law, tren ini menunjukkan bahwa "dalam jangka menengah, pemulihan sumber pendapatan ini masih tidak pasti, bahkan mungkin tidak akan terjadi.

3. Investasi energi terbarukan dan efisiensi energi yang ambisius dapat menciptakan 63 juta lapangan pekerjaan baru pada tahun 2050. Saat ini, lebih dari 11 juta orang bekerja di sektor energi terbarukan secara global. Di Amerika Serikat dan Eropa, 3,3 juta orang bekerja di industri efisiensi energi [21]. Menurut Badan Energi Internasional, sebagian besar pekerjaan efisiensi energi secara langsung membuka kesempatan kerja di tingkat daerah melalui usaha kecil dan menengah.

\section{HASIL DAN PEMBAHASAN}

\subsection{Hasil Analisis Resiko Pemanfaatan Energi Baru Terbarukan}

Mengelola risiko sebuah perusahaan adalah mengelola dampak yang dapat mengancam kegagalan pencapaian target dan sasaran perusahaan di masa yang akan datang akibat adanya ketidakpastian yang menjadi tugas manajemen untuk berupaya mencapai target dengan tingkat resiko yang sudah diprediksi. Manajemen risiko merupakan salah satu elemen penting dalam menjamenjalankan bisnis perusahaan karena semakin berkembangnya dunia perusahaan serta meningkatnya kompleksitas aktivitas perusahaan mengakibatkan meningkatnya tingkat ketidakpastian yang dihadapi perusahaan.

Dalam RUPTL 2021 - 2030 disebut juga Green RUPTL bahwa Indonesia memiliki target net zero emission pada tahun 2060 [22]. Rencana ini memerlukan kesinambungan antara penambahan kapasitas energi terbarukan dan memensiunkan pembangkit berbahan bakar fosil, dan pada tahun 2030 Indonesia memiliki target 28\% pembangkit dengan energi terbarukan atau 19,9 GW) dan 72\% pembangkit dengan bahan bakar fosil.

Tabel 2. Kondisi EBT di Indonesia tahun 2021 sebagai berikut :

\begin{tabular}{l|r|r|}
\multicolumn{1}{|c|}{ Jenis PLT } & Kapasity (MW) & \multicolumn{1}{c|}{$\%$} \\
\hline PLTU & 34.856 & 47,47 \\
\hline PLTG/GU/MG & 20.938 & 28,51 \\
\hline PLTA & 6.255 & 8,52 \\
\hline PLTD & 4.932 & 6,72 \\
\hline PLTP & 2.174 & 2,96 \\
\hline PLTU M/G & 2.060 & 2,81 \\
\hline PLT EBT & 2.215 & 3,02 \\
\hline \multicolumn{2}{|r|}{} \\
\hline
\end{tabular}

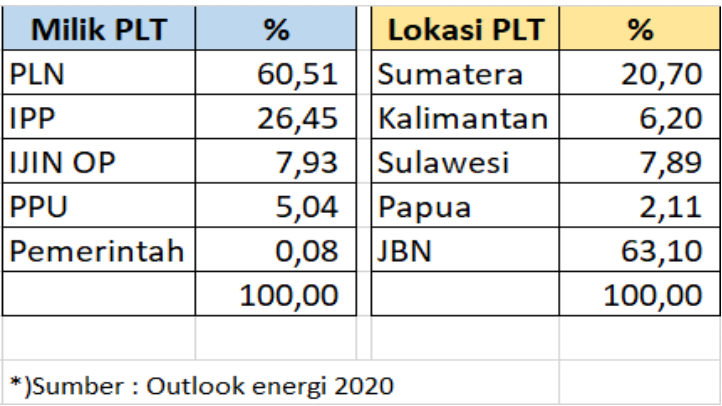


Berdasarkan data RUPTL 2021-2030 dan tabel 2, diketahui bahwa jumlah pembangkit listrik EBT terpasang di Indonesia saat ini sebesar 10,6 GW atau 14\% dari jumlah pembangkit dan selebihnya menggunakan energi fosil. Indonesia menuju target pembangunan EBT menjadi $19.900 \mathrm{MW}$ atau $28 \%$ pada tahun 2030 , sehingga masih memerlukan penambahan pembangunan pembangkit EBT sebanyak $9.300 \mathrm{MW}$ dari tahun 2021 sd 2030 (dalam kurun waktu 9 tahun ke depan) [22].

Menurut Buku Case Study Divisi Risk Management PLN, (2021) [23]; diuraikan bahwa Biomassa dan Integrated Gasification Combined Cycle (IGCC)+Carbon Capture and Storage (CCS) merupakan teknologi yang cukup menonjol dalam rencana bauran energi Indonesia. Pada salah satu rencana bauran energi tahun 2060 terlihat bahwa biomassa memiliki proporsi yang cukup signifikan, $250 \mathrm{GW}$ dari total $600 \mathrm{GW}$. Dalam skenario lain dapat terlihat juga pengembangan IGCC+CCS yang cukup signifikan sejak tahun 2030, meskipun sekarang teknologi ini masih belum terbukti dan dianggap belum layak, baik secara teknis maupun komersial. Kedua teknologi ini merupakan hal baru yang belum menjadi opsi terbukti untuk mencapai target net zero emission,

Tahun 2015 - 2020

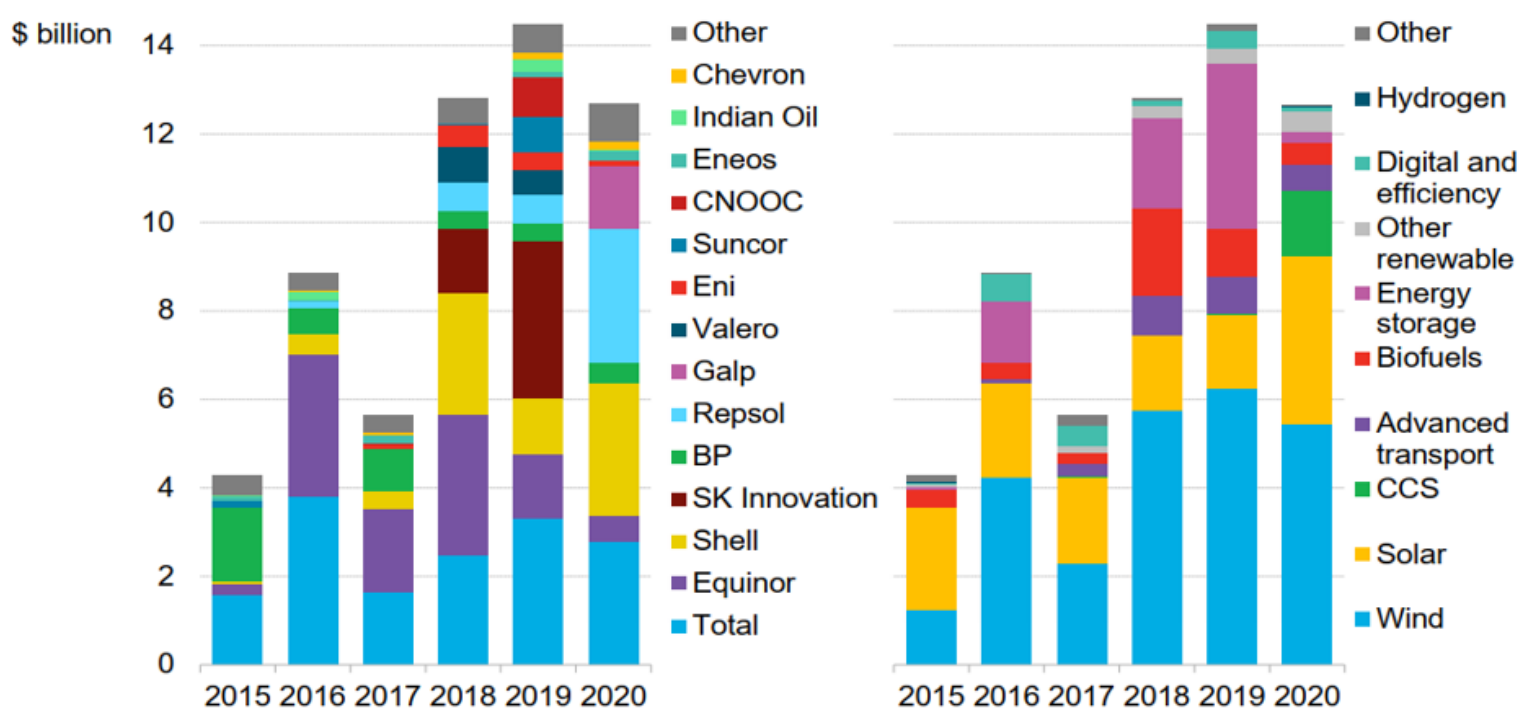

Source: BlooombergNEF, company disclosures. Note: analysis includes all completed deals, and estimated values for undisclosed deals. CCS data excludes non-commercial projects that have not disclosed investment values. Asset finance data may overstate investment by each company where project equity shares have not been disclosed.

Gambar 1. Investasi Energi Bersih Oleh Perusahaan Minyak dan Gas Bumi [21]

Meskipun kapasitas angin dan solar terus bertambah secara global, sumber energi terbarukan ini bukan merupakan opsi utama pada scenario Indonesia. Kondisi pasar saat ini sedang mengalami momentum pergerakan ke arah energi terbarukan. Tetapi tidak seluruh jenis teknologi diminati oleh investor global. Mencapai kondisi net zero emission memerlukan dukungan secara global, sehingga rencana yang tidak sejalan dengan kondisi pasar dapat menjadi risiko tersendiri yang berpotensi menyulitkan tercapainya target pada tahun 2060. 
Major barriers to invest in new large-scale generation

Regulatory uncertainty

Lack of coordination between ministries/other government

Institutions

Obtaining finance

Timely conclusion of PPPAs and permits

Standartd bankable PPA

with appropriate risk allocation

Availability of government guarantees

Adequancy of renewables feed in tariffs (“FiT")

Lack of transparency in

procurement and bidding of new project

Access to primary energy

T\&D information not ready
$83 \%$

\section{$73 \%$}

$67 \%$

\section{$63 \%$}

$57 \%$

$57 \%$

$50 \%$

$50 \%$

$43 \%$

$37 \%$

Gambar 2. Hambatan Terbesar Dalam Investasi Pembangkit Skala Besar di Indonesia [22] Sumber: Rencana Strategis 2015-2019 Kementrian Energi dan Sumberdaya Mineral

Berdasarkan gambar 2, terdapat beberapa hambatan dalam pengembangan investasi pembangkit skala besar di Indonesia, antara lain 5 terbesar yaitu [24] :

1. Ketidakpastian regulasi $-83 \%$

2. Kurangnya koordinasi antar kementerian/lembaga pemerintah lainnya - $73 \%$

3. Obstaining keuangan - $67 \%$

4. Kondisi tepat waktu PPI dan permints $-63 \%$

5. Tariff EBT (feed in tariff - FIT) $-50 \%$

Ad 1. Beberapa regulasi untuk mendukung kebijakan EBT di Indonesia dari sisi hulu sd hilir termasuk ketentuan dari PT PLN (Persero) yaitu sudah diterbitkannya; misal Permen tentang listrik EBT, pengaturan tariff EBT untuk menopang tumbuhnya EBT di Indonesia, pengaturan cofiring PLTU, pengaturan kendaraan listrik, dll. Namun kendalanya adalah regulasi yang sering berubah rubah dalam waktu yang cukup singkat sehingga implementasi regulasi tidak maksimal.

Ad 2. Koordinasi antara kementerian untuk mendukung EBT dari seluruh sector sudah ada termasuk BUMN. Beberapa BUMN ; PLN, Pertamina, Gas, Semen, dan lainnya menduukung upaya EBT dalam rangka reduce $\mathrm{CO} 2$ dan dampak gas rumah kaca - GRK.

Ad 3 - Hambatan yang paling besar dirasakan dalam pengembangan EBT di Indonesia adalah bagaimana mendapatkan financing / pendanaan. Masih diperlukan dukungan pemerintah dan menarik investor EBT dengan biaya paling murah serta dukungan perbankan.

Ad 4. Masih dirasakan oleh calon investor kesulitan dan birokrasi dalam pembangunan EBT di Indonesia, termasuk perijinan, proses yang sangat lama sd 2 tahun atau lebih dll yang ditumpangi oleh beberapa kepentingan maupun unsur 
politik. PLN masih focus untuk meningkatkan energi terjual dan efisiensi biaya operasi dan investasi tanpa meninggalkan produktifitas dan peluang pertumbuhan ke depan dalam rangka memperbaiki kinerja keuangannya.

Ad 5. Tarif EBT masih dirasa tinggi. Namun beberapa data menunjukkan bahwa secara bertahap tariff EBT mengalami penurunan. Diharapkan nantinya tariff EBT lebih rendah dari tarif dasar listrik atau tarif pembangkit energi fosil.

\subsection{Analisis Peluang Pembangunan Energi Baru Terbarukan}

Menjawab tantangan net zero emisi dan menuju clean energy yang sudah menjadi program dunia, maka tren menggembirakan terlihat bahwa kecenderungan pertumbuhan energi bersih dunia semakin naik sementara penggunaan energi bahan bakar fosil cenderung semakin menurun (ditunjukkan dalam gambar 3). Tantangannya adalah bagaimana mempercepat peningkatan energi bersih melalui pembangunan EBT dan mengurangi pembangkit energi fosil dengan untuk mencapai sasaran net zero emisi maupun mendukung pertumbuhan tenaga listrik di Indonesia [11][25].

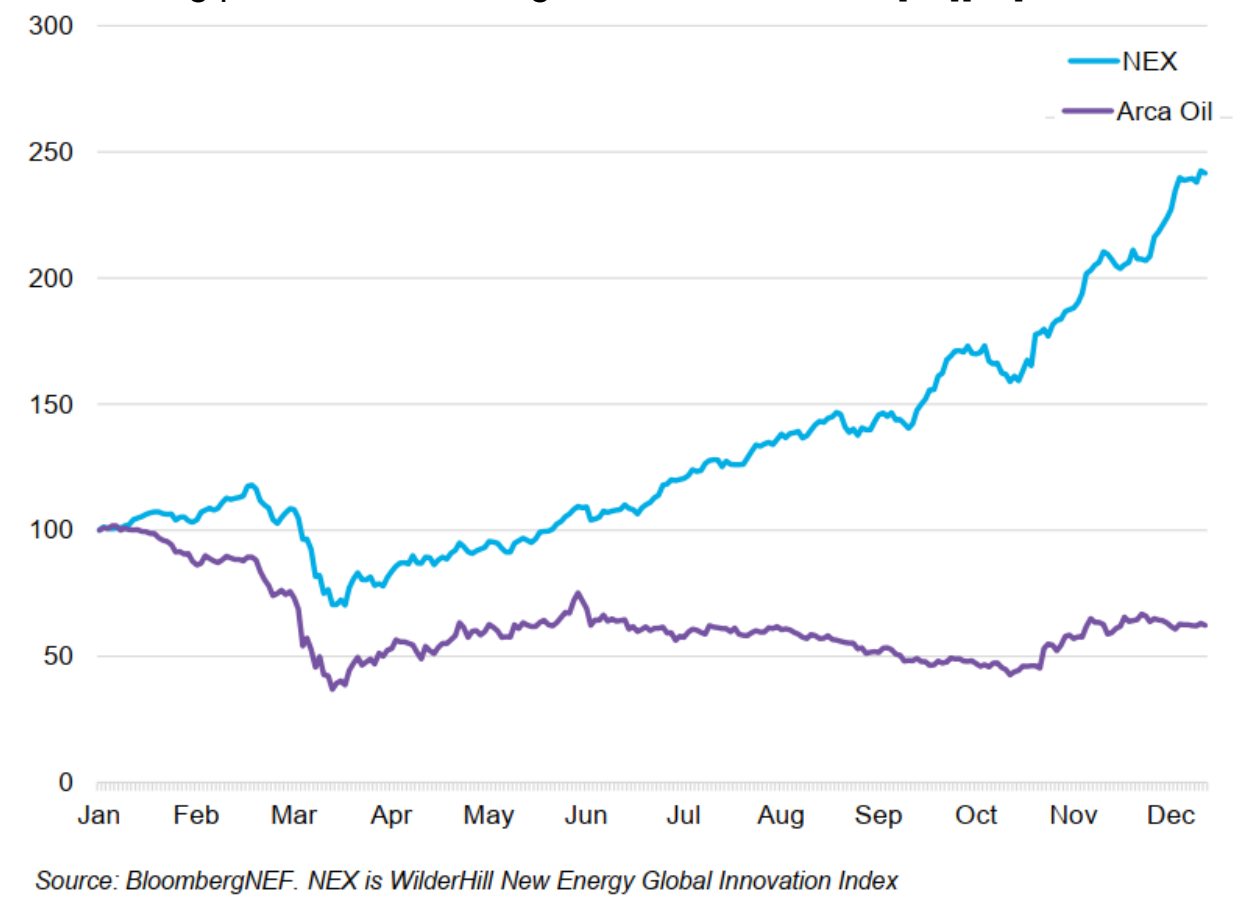

Gambar 3. Tren Pertumbuhan Clean Energy (NEX) dan Penggunaan BBM (Arca Oil) Tahun 2020 (Bulan Januari sd Desember)

Dalam kaitannya dengan sektor energi bersih, maka pada tahun keuangan 2020 telah disepakati sebuah mencatatkan komitmen investasi senilai USD 501,00 milyar atau setara dengan Rp. 7.500 trilliun, dimana terdapat peningkatan sebesar 9\% dari komitmen tahun sebelumnya. Dari komitmen USD 501 miliar tersebut. segmen energi terbarukan dipatok tertinggi yaitu 60\% atau sebesar USD 303 milyar atau Rp. 4.500 trilliun dari total komitmen investasi pada keseluruhan sektor transisi energi rendah karbon.

Investasi pada sektor energi bersih tersebut memiliki keunggulan yang melekat seperti risk adjusted return yang lebih tinggi dan menjanjikan cashflow proyek yang stabil. Selain itu, pada paket stimulus COVID-19 yang dijanjikan dari beberapa pemerintah, terutama negara Eropa dan Korea Selatan menjadikan green investment sebagai prioritas 
utama dalam rencana pemulihan ekonomi, sehingga hal ini merupakan iklim positif yang semakin mendorong tumbuhnya investasi energi bersih.

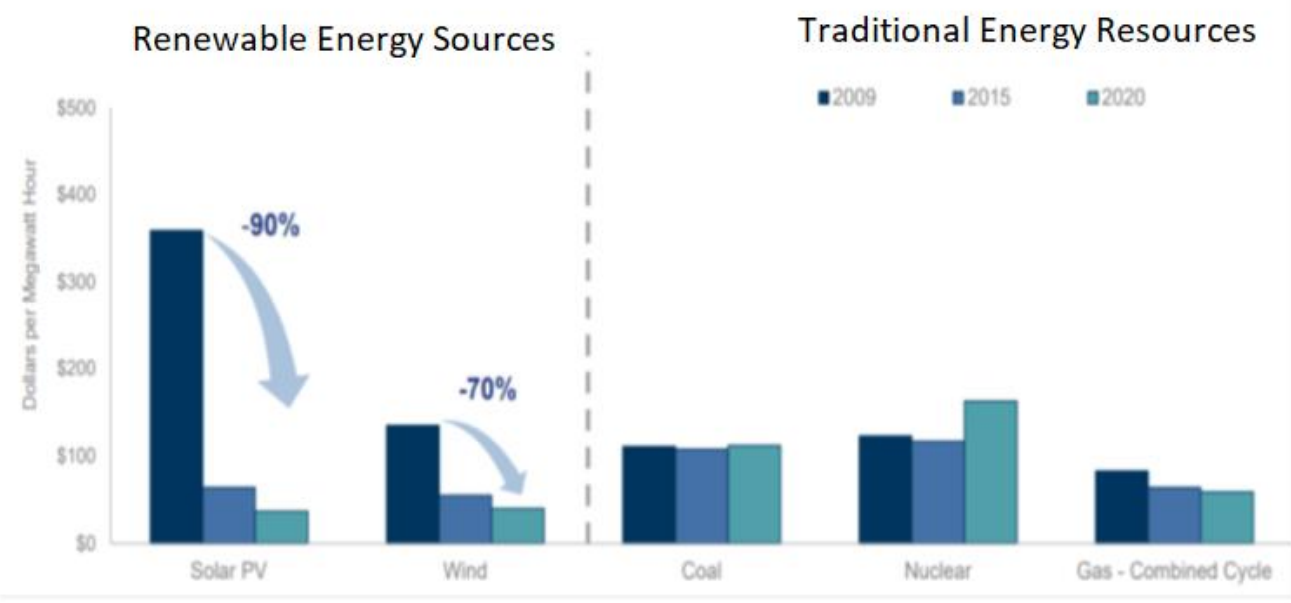

Gambar 4. Perubahan levelized cost dari pembangkit

Peluang harga EBT menurun diperlihatkan dalam gambar diatas khsusnya PLTS solar pv yang turun hampir 90\% tahun 2009 ke tahun 2020 . Demikian juga dengan energi angin yang turun sd $70 \%$ dari tahun 2009 sd 2020. Dan ini menjadi harapan dan peluang dalam pengembangan EBT dan mengurangi energi fosil. Sumber energi terbarukan merupakan teknologi yang sudah terbukti dapat memastikan transisi energi ini tercapai dalam beberapa decade mendatang. Dengan pertumbuhan konsumsi energi sebesar $82 \%$ sejak 2010, sumber energi bersih diekspektasikan sebagai sumber energi terbesar secara global, dengan estimasi pertumbuhan yang mencapai 137\% di tahun 2050. Sumber Energi dan/ atau Sumber Daya Energi ditujukan untuk modal pembangunan guna sebesar-besar kemakmuran rakyat, dengan cara mengoptimalkan pemanfaatannya bagi pembangunan ekonomi nasional, penciptaan nilai tambah di dalam negeri dan penyerapan tenaga kerja

\subsection{Tren Pertumbuhan Pembangkit dan Energi Terjual 10 Tahunan}

Melihat pertumbuhan demand listrik yang belum maksimal dan penambahan pembangkit listrik terus berlangsung dalam penyelesaian pembangunan 35 ribu MW, terjadi peningkatan reserve margin tenaga listrik PLN mencapai 125\%. Tantangan dan peluang bagi pemerintah dan PLN adalah bagimana upaya untuk meningkatkan beban atau konsumsi tenaga listrik di Indonesia. Terbukti pemerintah telah mendorong pertumbuhan konsumsi energi menuju energi bersih dengan membuat regulasi yang mendukung, seperti kemudahan dalam pembangunan EBT, subsidi triff EBT untuk merangsang minat investor serta menggiatkan industri dan penggunaan kendaraan listrik dengan berbagai kemudahan bagi produsen dan konsumen.

Dalam RUPTL 2021-2030 telah di rencanakan pertumbuhan ketenaga listrikan seperti terlihat pada table rencana pertumbuhan pembangkit dan rencana energi terjual dalam kurun waktu 10 tahun ke depan berikut ini [22]. 
Vol. 11, No. 2, Desember 2021, P-ISSN 2356-1505, E-ISSN 2656-9175

https://doi.org/10.33322/sutet.v11i2.1575

Tabel 3. RUPL 2021 - 2030 Penambahan Pembangkit EBT

\begin{tabular}{|l|r|r|r|r|r|r|r|r|}
\hline \multicolumn{1}{|c|}{ PLT } & PLTA, PLTM/H & PLTB & PLT Bio & PLTP & PLTS & $\begin{array}{c}\text { PLT EBT } \\
\text { Base }\end{array}$ & $\begin{array}{c}\text { Energi } \\
\text { Storage } \\
\text { System }\end{array}$ & TOTAL \\
\hline MW & 10.391 & 597 & 590 & 3.355 & 4.600 & 1.010 & 300 & 20.843 \\
\hline Prosentasi & 25,6 & 1,5 & 1,5 & 8,3 & 11,5 & 2,5 & 0,7 & 51,6 \\
\hline
\end{tabular}

*)Sumber RUPTL 2021-2030

Diharapkan pertumbuhan pembangkit khsusnya pembangkit energi bersih mendorong pertumbuhan konsumsi tenaga listrik perkapita Indonesia yang saat ini per September 2021 baru mencapai 1,1 MWh per kapita yang ditargetkan mencapai 2,5 MWh per kapita pada tahun 2025 DAN 7,0 MWh per kapita pada tahun 2050 sesuai PP No 79 tahun 2014 dengan meningkatkan pertumbuhan pembangkit dan ketersediaan tenaga listrik yang memadai.

Tabel 4. Komposisi Produksi Energi Listrik Berdasarkan Jenis Bahan Bakar (GWh)

\begin{tabular}{|c|c|c|c|c|c|c|c|c|c|c|c|}
\hline No. & Jenis Bahan Bakar & 2021 & 2022 & 2023 & 2024 & 2025 & 2026 & 2027 & 2028 & 2029 & 2030 \\
\hline 1 & Air & 18.750 & 18.629 & 20.531 & 22.454 & 28.291 & 31.802 & 33.615 & 37.350 & 41.574 & 44.256 \\
\hline 2 & Panas Bumi & 15.849 & 16.571 & 18.009 & 18.875 & 26.785 & 30.550 & 31.441 & 34.380 & 36.173 & 43.215 \\
\hline \multirow[t]{6}{*}{3} & EBT Lain & 2.031 & 3.541 & 6.044 & 8.958 & 26.449 & 22.681 & 22.516 & 19.240 & 16.519 & 9.655 \\
\hline & Surya & 106 & 823 & 1.241 & 1.547 & 2.255 & 2.339 & 2.399 & 2.469 & 2.551 & 2.630 \\
\hline & Bayu & 477 & 477 & 567 & 1.880 & 2.839 & 2.898 & 3.088 & 3.087 & 3.088 & 3.087 \\
\hline & Sampah & 59 & 91 & 91 & 285 & 1.615 & 1.601 & 1.624 & 1.605 & 1.603 & 1.596 \\
\hline & Biomas & 777 & 1.879 & 3.874 & 5.003 & 19.666 & 15.763 & 15.323 & 11.991 & 9.182 & 2.248 \\
\hline & Lainnya & 612 & 271 & 271 & 243 & 74 & 80 & 82 & 88 & 95 & 94 \\
\hline \multirow[t]{3}{*}{4} & Gas & 45.464 & 50.914 & 50.953 & 52.489 & 51.485 & 51.956 & 53.233 & 53.513 & 54.945 & 56.282 \\
\hline & Gas & 23.811 & 24.509 & 22.105 & 20.768 & 20.506 & 20.903 & 20.708 & 20.070 & 20.491 & 19.986 \\
\hline & LNG & 21.653 & 26.405 & 28.848 & 31.721 & 30.979 & 31.053 & 32.525 & 33.443 & 34.454 & 36.296 \\
\hline \multirow{5}{*}{5} & BBM & 9.326 & 5.622 & 4.069 & 1.839 & 1.417 & 1.432 & 1.502 & 1.606 & \begin{tabular}{|l|l|}
1.697 \\
\end{tabular} & 1.805 \\
\hline & HSD & 8.142 & 5.384 & 3.831 & 1.601 & 1.417 & 1.432 & 1.502 & 1.606 & 1.697 & 1.805 \\
\hline & MFO & 1.184 & 238 & 238 & 238 & - & - & - & - & - & - \\
\hline & IDO & - & - & - & - & - & - & - & - & - & - \\
\hline & $\mathrm{HFO}$ & - & - & - & - & - & - & - & - & - & - \\
\hline 6 & Batubara & 198.103 & 209.128 & 219.795 & 231.446 & 220.032 & 233.074 & 244.352 & 257.953 & 270.940 & 284.637 \\
\hline 7 & Potensi EBT & - & - & - & - & - & 534 & 1.765 & 2.545 & 3.585 & 5.246 \\
\hline \multirow[t]{2}{*}{8} & Impor & 954 & - & - & - & - & - & - & - & - & - \\
\hline & Jumlah & 290.477 & 304.405 & 319.401 & 336.061 & 354.459 & 372.029 & \begin{tabular}{|l|}
388.424 \\
\end{tabular} & 406.587 & 425.433 & 445.096 \\
\hline
\end{tabular}

Jumlah produksi energi listrik Indonesia tahun 2020 mencapai 250 TWh, berdasarkan tabel 3 pada tahun 2030 ditargetkan produksi energi listrik sebesar 445 TWh atau target kenaikan produksi listrik sebesar 195 TWh atau 78\% dari tahun 2020.

Tabel 5. Proyeksi Penjualan Tenaga Listrik Indonesia (GWh) Skenario Optimis

\begin{tabular}{|c|c|c|c|c|c|c|c|c|c|c|}
\hline Uraian & 2021 & 2022 & 2023 & 2024 & 2025 & 2026 & 2027 & 2028 & 2029 & 2030 \\
\hline Rumah Tangga & 117.742 & 122.626 & 127.603 & 132.697 & 137.967 & 143.121 & 148.456 & 153.956 & 159.527 & 165.374 \\
\hline Bisnis & 46.172 & 49.962 & 53.653 & 57.606 & 61.842 & 66.270 & 70.780 & 75.562 & 80.623 & 85.941 \\
\hline Publik & 16.822 & 17.795 & 18.840 & 19.950 & 21.106 & 22.306 & 23.544 & 24.824 & 26.139 & 27.514 \\
\hline Industri & 75.641 & 82.018 & 87.712 & 94.810 & 101.130 & 107.507 & 113.389 & 118.988 & 124.318 & 130.007 \\
\hline Total & 256.376 & 272.401 & 287.808 & 305.062 & 322.045 & 339.203 & 356.170 & 373.330 & 390.607 & 408.836 \\
\hline Pertumbuhan (\%) & 6,3 & 6,3 & 5,7 & 6,0 & 5,6 & 5,3 & 5,0 & 4,8 & 4,6 & 4,7 \\
\hline $\begin{array}{l}\text { Konsumsi tenaga listrik } \\
\text { per kapita (kWh/kapita)* }\end{array}$ & 946 & 996 & 1.043 & 1.095 & 1.146 & 1.197 & 1.247 & 1.296 & 1.346 & 1.398 \\
\hline $\begin{array}{l}\text { Beban Puncak Non- } \\
\text { Coincident (MW) }\end{array}$ & 43.289 & 45.962 & 48.592 & 51.366 & 54.096 & 56.786 & 59.452 & 62.182 & 64.930 & 67.984 \\
\hline
\end{tabular}

*) $\mathrm{kWh}$ pada konsumsi listrik per kapita hanya melihat konsumsi listrik PLN 
Pertumbuhan penjualan tenaga listrik pada tahun 2021 - 2030 ditargetkan rata rata $4,7 \%$ dan pertumbuhan penjualan berpeluang lebih tinggi dari $4,7 \%$ dengan semakin membaiknya pertumbuhan ekonomi dan pertumbuhan industri di era energi bersih.

\section{KESIMPULAN DAN SARAN}

\subsection{Kesimpulan}

Berdasarkan data RUPTL 2021-2030 dan penjelasan pada tabel, diketahui bahwa jumlah pembangkit listrik EBT terpasang di Indonesia saat ini sebesar 10,6 GW atau 14\% dari jumlah pembangkit dan selebihnya menggunakan energi fosil. Indonesia menuju target pembangunan EBT menjadi $19.900 \mathrm{MW}$ atau $28 \%$ pada tahun 2030 , sehingga masih memerlukan penambahan pembangunan pembangkit EBT sebanyak $9.300 \mathrm{MW}$ dari tahun 2021 sd 2030 (dalam kurun waktu 9 tahun ke depan). Sumber energi terbarukan merupakan teknologi yang sudah terbukti dapat memastikan transisi energi ini tercapai dalam beberapa decade mendatang. Dengan pertumbuhan konsumsi energi sebesar $82 \%$ sejak 2010, sumber energi bersih diekspektasikan sebagai sumber energi terbesar secara global, dengan estimasi pertumbuhan yang mencapai $137 \%$ di tahun 2050 . Pertumbuhan pembangkit khsusnya pembangkit energi bersih mendorong pertumbuhan konsumsi tenaga listrik perkapita Indonesia yang ditargetkan mencapai 1,4 MWh perkapita pada tahun 2024, melalui upaya peningkatan yang ditargetkan sebesar $445 \mathrm{TWh}$ atau target kenaikan produksi listrik sebesar 195 TWh atau 78\% dari tahun 2020 serta pertumbuhan penjualan tenaga listrik pada tahun 2021 - 2030 ditargetkan rata rata 4,7\%.

\subsection{Saran}

Walaupun kondisi Investasi pada sektor energi bersih tersebut memiliki keunggulan yang melekat seperti risk adjusted return yang lebih tinggi dan menjanjikan cashflow proyek yang stabil. Selain itu, pada paket stimulus COVID-19 yang dijanjikan dari beberapa pemerintah, terutama negara Eropa dan Korea Selatan menjadikan green investment sebagai prioritas utama dalam rencana pemulihan ekonomi, disarankan pemerintah dan PLN dapat membuat regulasi dan implementasi yang mengrahkan pemanfaatkan iklim positif yang semakin mendorong tumbuhnya investasi energi bersih.

Mewujudkan upaya untuk mencapai target pertumbuhan konsumsi listrik per kapita, peningkatan jumlah pembangkit energi bersih dan peningkatan pertumbuhan penjualan tenaga listrik sesuai kebijakan RUPTL 2021-2030 yang sudah ditetapkan pemerintah.

1. Untuk melakukan dekarbonisasi industri, kita harus mendorong diversifikasi energi industri ke teknologi rendah karbon seperti penggunaan panas matahari terkonsentrasi untuk air panas, hidrogen atau ammonia yang akan mendorong pertumbuhan pembangkit EBT

\section{UCAPAN TERIMAKASIH}

Penulis mengucapkan terima kasih kepada Institut Teknologi PLN yang telah memberikan dana untuk pelaksanaan penelitian ini. 


\section{DAFTAR PUSTAKA}

[1] Pusat Teknologi Konversi Dan Konservasi Energi (PTKKE), "Kajian Perkembangan Sistem Metering Kelistrikan Di Indonesia Menuju Advanced Metering Infrastructure," Jakarta, 2015.

[2] Samudin Harsanto, "Statistik Listrik 'Electric Statistic' 2013-2018," BPS-Statistic Indonesia, 2018.

[3] Y. Jiang, K. H. Park, and C. H. Jeon, "Feasibility study of co-firing of torrefied empty fruit bunch and coal through boiler simulation," Energies, vol. 13, no. 12, 2020, doi: 10.3390/en13123051.

[4] P. Mandarani, "Perancangan Dan Implementasi User Interface Berbasis Web Untuk Monitoring Suhu, Kelembaban Dan Asap Pada Ruangan Berbeda Dengan Memanfaatkan Jaringan Local Area Network," vol. 2, no. 2, pp. 37-42, 2014.

[5] S. Suganal and G. K. Hudaya, "Bahan bakar co-firing dari batubara dan biomassa tertorefaksi dalam bentuk briket (Skala laboratorium)," J. Teknol. Miner. dan Batubara, vol. 15, no. 1, pp. 31-48, 2019, doi: 10.30556/jtmb.vol15.no1.2019.971.

[6] P. P. Persero, "Meter listrik pintar," Jakarta, 2018.

[7] P. K. W. Likun, H. Zhang, and R. Xiao, "Co-firing behaviors and kinetics of different coals and biomass," J. Biobased Mater. Bioenergy, vol. 11, no. 2, 2017, doi: 10.1166/jbmb.2017.1655.

[8] D. Rudenko and G. Tanasov, "The determinants of energy intensity in Indonesia," Int. J. Emerg. Mark., 2020, doi: 10.1108/IJOEM-01-2020-0048.

[9] J. Li, X. Zhang, W. Yang, and W. Blasiak, "Effects of Flue Gas Internal Recirculation on NOx and SOx Emissions in a Co-Firing Boiler," Int. J. Clean Coal Energy, vol. 02, no. 02, 2013, doi: 10.4236/ijcce.2013.22002.

[10] S. Fogarasi and C. C. Cormos, "Technico-economic assessment of coal and sawdust co-firing power generation with CO2 capture," J. Clean. Prod., vol. 103, 2015, doi: 10.1016/j.jclepro.2014.07.044.

[11] "UU No. 30 Tahun 2007 tentang Energi [JDIH BPK RI]." [Online]. Available: https://peraturan.bpk.go.id/Home/Details/39928/uu-no-30-tahun-2007. [Accessed: 02-Jan-2022].

[12] Y. Sunitiyoso, J. P. Mahardi, Y. Anggoro, and A. Wicaksono, "New and renewable energy resources in the Indonesian electricity sector: a systems thinking approach," undefined, vol. 14, no. 6, pp. 1381-1403, Oct. 2020, doi: 10.1108/IJESM-11-20190019.

[13] S. H. Goh, "Barriers to low-carbon warehousing and the link to carbon abatement: A case from emerging Asia," Int. J. Phys. Distrib. Logist. Manag., vol. 49, no. 6, pp. 679704, Aug. 2019, doi: 10.1108/IJPDLM-10-2018-0354.

[14] D. Cebrucean, V. Cebrucean, and I. Ionel, "Modeling and performance analysis of subcritical and supercritical coal-fired power plants with biomass co-firing and $\mathrm{CO} 2$ capture," Clean Technol. Environ. Policy, vol. 22, no. 1, 2020, doi: 10.1007/s10098019-01774-1.

[15] L. Gaslac, S. Willis, G. Quispe, and C. Raymundo, "A hybrid energy system based on renewable energy for the electrification of low-income rural communities," IOP Conf. Ser. Earth Environ. Sci., vol. 168, no. 1, Jul. 2018, doi: 10.1088/17551315/168/1/012005. 
[16] "Global Investors Move Into Renewable Infrastructure Reviewing the World's Top Renewable Energy Financiers," 2021.

[17] "PP No. 79 Tahun 2014 tentang Kebijakan Energi Nasional [JDIH BPK RI]." [Online]. Available: $\quad$ https://peraturan.bpk.go.id/Home/Details/5523/pp-no-79-tahun-2014. [Accessed: 02-Jan-2022].

[18] T. Balikhina, A. Al Maqousi, A. Albanna, and F. Shhadeh, "System architecture for smart home meter," in Proceedings of 2nd International Conference on the Applications of Information Technology in Developing Renewable Energy Processes and Systems, IT-DREPS 2017, 2018, vol. 2018-Janua, pp. 1-5, doi: 10.1109/ITDREPS.2017.8277811.

[19] R. R. A. Siregar, Y. K. Ningsih, P. Palupiningsih, and B. Prayitno, "Smart kWh Meter Model with Energy Control and Monitoring on Low Voltage Electricity," pp. 227-232, Dec. 2020, doi: 10.2991/AER.K.201221.039.

[20] M. Otoom, N. Otoum, M. A. Alzubaidi, Y. Etoom, and R. Banihani, "An loT-based framework for early identification and monitoring of COVID-19 cases," Biomed. Signal Process. Control, vol. 62, 2020, doi: 10.1016/j.bspc.2020.102149.

[21] "Energy Transition Investment Trends 2021 | BloombergNEF." [Online]. Available: https://about.bnef.com/energy-transition-investment/. [Accessed: 02-Jan-2022].

[22] Menteri ESDM RI, "Rencana Usaha Penyediaan Tenaga Listrik (RUPTL) PT PLN (Persero) 2021-2030.," Rencana Usaha Penyediaan Tenaga List. 2021-2030, pp. 2019-2028, 2021.

[23] Wibisana Bagus Santosa, "Analisis pendanaan proyek PT. PLN (Persero) studi kasus pembangkit listrik tenaga uap (PLTU) Indramayu = Project financing analysis of PT. PLN (Persero) study case on Indramayu coal-fired power plant project." Universitas Indonesia, 2012.

[24] Dewan Energi Nasional, Bauran Energi Nasional 2020. 2020.

[25] R. R. A. Siregar, H. Sikumbang, and J. Pasaribu, "Model Pengisian Pulsa Listrik kWh Meter," vol. 16, no. 1, pp. 39-54, 2018.

[21] [26] Samsurizal, S., Christiono, C., \& Husada, H. Studi Kelayakan Pemanfaatan Energi Matahari Sebagai Pembangkit Listrik Tenaga Surya Di Dusun Toalang. Setrum: Sistem Kendali-Tenaga-elektronika-telekomunikasi-komputer, 9(1), 75-83. 2020 